\title{
EL PATRIMONIO AGRARIO COMO MARCO DE REFERENCIA DE LOS PAISAJES CULTURALES: CRITERIOS PARA SU DELIMITACIÓN Y PROTECCIÓN
}

\section{AGRICULTURAL HERITAGE AS A FRAME OF REFERENCE FOR CULTURAL LANDSCAPES: CRITERIA FOR THEIR DELIMITATION AND PROTECTION}

José CASTILLO RUIZ

Universidad de Granada

Recibido: $15 / 07 / 2021 \quad$ Aceptado: $22 / 11 / 2021$

\section{RESUMEN}

Aunque la figura de paisaje cultural es la más utilizada para proceder al reconocimiento y actuación sobre los espacios agrarios, ésta presenta importantes carencias en aspectos fundamentales como la delimitación de dichos espacios o los mecanismos y medidas establecidos para su protección. Para poder avanzar en la mejora de estas deficiencias es necesario aplicar sobre los paisajes culturales agrarios los principios que rigen el Patrimonio Agrario, que es el marco conceptual que debería guiar cualquier actuación sobre los bienes agrarios, incluidos los paisajes culturales, que no son más que un instrumento legal, una tipología de bien inmueble (tal y como intentamos demostrar al principio de nuestro artículo), para abordar la tutela de la dimensión territorial (por otro lado, la más importante) de los bienes agrícolas, ganaderos y silvícolas.

Palabras clave: Patrimonio Agrario. Paisaje Cultural. Patrimonio Mundial. Vega de Granada. 


\section{ABSTRACT}

Even though the concept of cultural landscape is the most commonly used when it comes to recognising and acting on agricultural spaces, it has important shortcomings in key aspects, like the delimitation of such spaces or the mechanisms and measures established for their protection. In order to overcome these shortcomings, the principles of Agricultural Heritage must be applied to agricultural cultural landscapes. These principles are the conceptual framework that any action on agricultural assets should abide by, including cultural landscapes. Cultural landscapes are nothing but a mere legal instrument, a typology of immovable property, as we tried to prove at the beginning of our article, that is used to address the protection of the territorial dimension, the most important dimension, of agricultural, livestock and forestry assets.

Keywords: Agrarian Heritage. Cultural Landscape. World Heritage. Vega de Granada.

\section{1.- LOS LÍMITES DEL PAISAJE CULTURAL COMO MECANISMO DE PROTECCIÓN DEL PATRIMONIO CULTURAL. SU RECLAMA- CIÓN COMO TIPOLOGÍA DE BIEN INMUEBLE.}

Quisiéramos empezar este trabajo partiendo de una constatación que nos parece muy relevante en relación a la situación real que presentan los paisajes culturales en nuestro país y referida a la cuestión que más nos interesa, la de éstos como mecanismo (en cuanto a tipología de bien cultural) de protección de los territorios (o de otro tipo de espacios, según la dimensión que le otorguemos a esta figura). Y esta constatación es que existe una enorme distancia entre las escasísimas declaraciones como BIC (u otras categorías legales) de paisajes culturales realizadas en España (Fig. 1) ${ }^{1}$, a pesar de que cada vez son más las

1 .- Resulta muy difícil elaborar una lista de los ámbitos patrimoniales de carácter territorial declarados en España que podrían corresponderse con paisajes culturales, ya que en la mayoría de los casos la figura utilizada para declararlos no es la de paisaje cultural, todavía muy incipiente en cuanto a su utilización, sino otras afines o relacionadas como la de conjunto histórico, sitio histórico, itinerario cultural, incluso una ya derogada, pero de gran modernidad en su momento, como la de paisaje pintoresco. Teniendo en cuenta esto, las declaraciones realizadas en España que podríamos considerar como correspondientes a los paisajes culturales, son las siguientes: Decreto 89/2014, de 3 de junio, por el que se califica como Bien Cultural, con la categoría de Conjunto Monumental, el Paisaje Cultural del Vino y el Viñedo de la Rioja Alavesa (Álava); Decreto 20/2015, de 12 de junio, por el que se declara bien de interés cultural «El paisaje cultural del Vino y el Viñedo de La Rioja»; Decreto 166/2018, de 27 de diciembre, por el que se declara bien de interés cultural el paisaje cultural de la Ribeira Sacra; Decreto 49/2018, de 26 de abril, por el que se declara bien de interés cultural, el archipiélago de Sálvora, con la categoría de paisaje cultural. Decreto 185/2013, de 26 de marzo, por el que se califica como Bien Cultural, con la categoría de 


\section{leyes de patrimonio cultural de las Comunidades Autónomas que la están reco- nociendo como tal tipología ${ }^{2}$, y la multitud de propuestas y proyectos de estudio y catalogación de paisajes culturales puestos en marcha por todo tipo de admi- nistraciones, instituciones o investigadores ${ }^{3}$, incluyendo la existencia desde}

Conjunto Monumental, el Paisaje Cultural del Valle Salado de Añana (Álava); Decreto 43/2017, de 14 de marzo, por el que se inscribe en el Catálogo General del Patrimonio Histórico Andaluz como Bien de Interés Cultural, con la tipología de Zona Patrimonial, el Valle del Darro, en los términos municipales de Beas de Granada, Granada y Huétor Santillán, Granada (esta declaración fue anulada por el Tribunal Superior de Justicia de Andalucía el 16 de junio de 2020 por motivos formales a raíz del recurso presentado por un propietario afectado, el cual no había sido notificado de la incoación de la declaración como Zona Patrimonial); Decreto 125/2021, de 13 de abril, por el que se declara como Bien Cultural de Protección Especial, con la categoría de Paisaje Cultural, San Juan de Gaztelugatxe, sito en Bermeo (Bizkaia); Anuncio de 15 de marzo de 2021, relativo al cambio de categoría del Conjunto Histórico designada inicialmente en el expediente incoado a favor de la declaración como Bien de Interés Cultural de la Ermina de la Virgen de Los Reyes, Cueva del Caracol y Camino de la Virgen, por la categoría de Paisaje Cultural pasado a denominarse Paisaje Cultural de la Virgen de Los Reyes; Resolución de 25 de noviembre de 2020, de la Dirección General de Patrimonio Cultural de la Comunidad de Madrid, por la que se incoa el expediente de declaración de Bien de Interés Cultural, en la categoría de Paisaje Cultural, de la Presa de El Gasco y el Canal del Guadarrama, en los municipios de Galapagar, Las Rozas de Madrid y Torrelodones (Madrid); Acuerdo del Gobierno de Navarra, de 15 de marzo de 2010, por el que se revoca el Acuerdo del Gobierno de Navarra de 8 de febrero de 2010, al objeto de corregir los errores en él advertidos, y se declara nuevamente Bien de Interés Cultural, con categoría de Paisaje Cultural, las Palomeras de Etxalar, sitas en Etxalar (Navarra).

2 .- Las leyes de patrimonio cultural españolas que incluyen la tipología de paisaje cultural de forma expresa, todas ellas promulgadas por las Comunidades Autónomas, ya que ésta no está contemplada en la LPHE de 1985 (aunque el día 23 de junio de 2021 se anunció por parte del Ministerio de Cultura que se iniciaban los trámites parlamentarios para modificar dicha ley, dando cabida, entre otras novedades, precisamente a la figura de paisaje cultural) son las siguientes: la Ley 11/1998, de 13 de octubre, de Patrimonio Cultural de Cantabria, donde nos encontramos, dentro de la categoría de lugares culturales, con la figura de paisaje cultural; la Ley 7/2004, de 18 de octubre, de Patrimonio Cultural, Histórico y Artístico de La Rioja, la cual incluye, también dentro de la categoría de Lugares Culturales, la figura de paisaje cultural; la Ley Foral 14/2005, de 22 de noviembre, del Patrimonio Cultural de Navarra; la Ley 4/2007, de 16 de marzo, de Patrimonio Cultural de la Comunidad Autónoma de la Región de Murcia; la Ley 3/2013, de 18 de junio, de Patrimonio Histórico de la Comunidad de Madrid; la Ley 11/2019, de 25 abril, de Patrimonio Cultural de Canarias y la Ley 5/2016, de 4 de mayo, del Patrimonio Cultural de Galicia. Mención especial merece la figura de Zona Patrimonial (Verdugo Santos, 2005), contenida en la Ley 14/2007, de 26 de noviembre, del Patrimonio Histórico de Andalucía, la cual podemos considerar como equivalente a la del paisaje cultural.

3 .- De los innumerables proyectos de este tipo (y al margen de los contenidos en las diferentes leyes de paisajes promulgadas en España como la de Galicia o Cataluña) destacamos, por la complejidad, entidad y continuidad en el tiempo, los siguientes: el Registro de Paisajes de Interés Cultural de Andalucía (R-PICA) (https://repositorio.iaph.es/handle/11532/324406) (FERNÁNDEZ CACHO, S. et al., "Balance y perspectivas del Registro de Paisajes de Interés Cultural de Andalucía", $P H, \mathrm{n}^{\circ} 88$, octubre 2015, pp. 166-189); los Lugares de excepcional valor paisajístico de Asturias (LEVPAS) (FERNÁNDEZ SALINAS V., "Los paisajes de interés cultural de Asturias", Revista de geografia Ería, n 91, 2013, pp. 129149); el Atlas de los Paisajes de Castilla-La Mancha (https://www.castillalamancha.es/node/54537), los diferentes catálogos de paisaje y resto de productos y actividades desarrollados por el prestigioso L'Observatori del Paisatge de Catalunya (http://www.catpaisatge.net/esp/index.php), el Catálogo de Paisajes de Relevancia Regional de las Comunitat Valenciana (http://politicaterritorial.gva.es/es/web/planificacion-territorial-e-infraestructura-verde/paisatges-de-rellevancia-regional) o, dentro de la multitud de proyectos de investigación realizados, los dirigidos por María del Mar Lozano Bartolozzi, por ejemplo el 
2012 de un Plan Nacional de Paisaje Cultural ${ }^{4}$ (hecho éste que resulta coincidente con la atención preferente otorgada por la UNESCO a las candidaturas que se presenten bajo esta tipología para ser declaradas Patrimonio Mundial ${ }^{5}$ ). Esto provoca una enorme confusión en torno a esta figura, ya que la percepción (nunca mejor dicho) que se extrae de esta situación es que en España existe un alto grado de reconocimiento, valoración y protección de los paisajes culturales, hecho éste que consideramos queda muy alejado de la realidad.

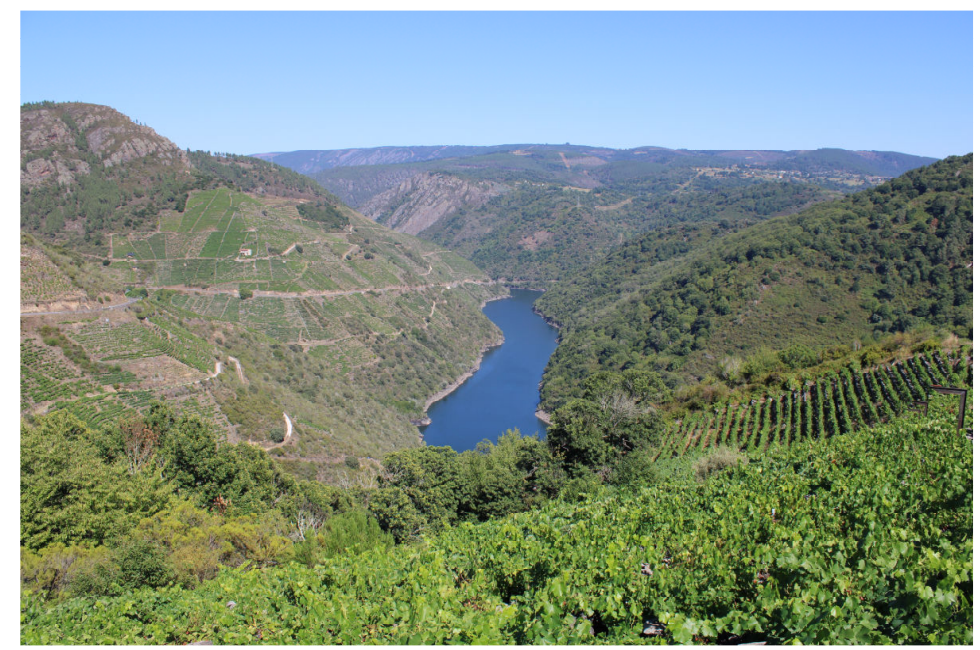

Fig. 1.- Viñedos en la Ribeira Sacra (Doade, Sober, Lugo). José Castillo Ruiz.

Aunque esta escasez de declaraciones es achacable también a lo novedoso de la tipología y al todavía limitado reconocimiento de la misma en nuestra legislación, sin embargo, transluce una situación de mayor calado y que puede resultar preocupante desde la perspectiva general de la tutela del patrimonio cultural.

titulado "Entre Toledo y Portugal: miradas y reflexiones contemporáneas en torno a un paisaje modelado por el Tajo" (Proyecto de Investigación I+D+I del Ministerio de Economía y Competitividad (HAR201021835) (LOZANO BARTOLOZZI, M ${ }^{\text {a }}$ del M. y MÉNDEZ HERNÁN, V. (coords. y eds.), Patrimonio cultural vinculado al agua. Paisaje, urbanismos, arte, ingeniería y turismo, Mérida, Editorial Regional de Extremadura, 2014.

4 .- CARRIÓN GÚTIEZ, A., Plan Nacional de Paisaje Cultural, Madrid, Ministerio de Educación, Cultura y Deporte, 2015.

5 .- Ver al respecto FERNÁNDEZ SALINAS, V. y SILVA PÉREZ, R., "Criterios para la identificación y selección de paisajes españoles susceptibles de ser incluidos en la lista del Patrimonio Mundial de UNESCO", Boletín de la Asociación de Geógrafos Españoles, 2015, nº. 68, p. 253-278 y FERNÁNDEZ SALINAS, V. y SILVA PÉREZ, R., "Deconstruyendo los paisajes culturales de la Lista del Patrimonio Mundial de la Unesco", Cuadernos Geográficos, nº 55, 2016, pp. 176-197. 
Por un lado, responde a una importante reticencia manifestada, podemos decir que desde el ámbito paisajístico, a utilizar la legislación de patrimonio cultural, a través de la tipología de paisaje cultural o de otras semejantes, como mecanismo para la protección de estos espacios. Esto nos remite a la importante confrontación que existe en este campo paisajístico entre los que defienden la condición común del paisaje, de estado general de cualquier lugar y territorio, por lo que lo cultural (lo patrimonial) sólo sería una cualidad de algunos de esos paisajes (es la caracterización defendida por el Convenio Europeo del Paisaje del año 2000, donde se define el paisaje como "cualquier parte del territorio tal como la percibe la población, cuyo carácter sea el resultado de la acción y la interacción de factores naturales y/o humanos "6), y los que se centran en su condición excepcional, por lo que el paisaje se identificaría exclusivamente con los paisajes culturales (posición defendida por la $\mathrm{UNESCO}^{7}$ y por la mayoría de leyes de patrimonio cultural que han incorporado esta figura de los paisajes culturales). Una disputa que no es sólo teórica (con propuestas conciliadoras como las de paisajes patrimoniales ${ }^{8}$ ) sino que tiene una gran trascendencia en el ámbito tutelar, ya que acaba determinando los mecanismos de protección utilizados para los mismos, de nuevo sometidos a una importante pugna entre la utilización exclusiva de los instrumentos urbanísticos y de gestión y los derivados de la legislación patrimonial (especialmente a través de su declaración como BIC).

Por otro lado, en esta situación subyace una incapacidad de la administración cultural para poder afrontar los enormes retos que supone la aplicación a los paisajes culturales del complejo y exigente sistema de protección instituido para los bienes inmuebles de conjunto en nuestra legislación de patrimonio cultural (y que tanta aplicación ha tenido ya en el caso de los conjuntos históricos). Una incapacidad que tiene que ver, no con lo acertado o no de este sistema de tutela, sino con la endémica falta de medios técnicos, económicos y humanos de la

6 .- Ver al respecto: FERNÁNDEZ LACOMBA, J., ROLDÁN, F. y ZOIDO, F. (coord.), Territorio y patrimonio. Los paisajes andaluces, Sevilla, Consejería de Cultura, Comares, 2003 y ZOIDO, F. y VENEGAS, C. (Coord.), Paisaje y Ordenación del Territorio, Sevilla, Consejería de Obras Públicas y Transportes y Fundación Duques de Soria, 2002.

7 .- Como es sabido la UNESCO reconoce por primera vez la tipología de paisaje cultural en 1992, el cual es definido, según aparece recogido en las Directrices Operativas para la aplicación de la Convención del Patrimonio Mundial Natural y Cultural de la siguiente forma: "Cultural landscapes are cultural properties and represent the "combinedworks of nature and of man" designated in Article 1 of the Convention. They are illustrative of the evolution of human society and settlement over time, under the influence of the physical constraints and/or opportunities presented by their natural environment and of successive social, economic and cultural forces, both external and internal" (UNESCO, The Operational Guidelines for the Implementation of the World Heritage Convention. WHC.19/01 10 July 2019 [Consulta 28/06/2021. http://whc.unesco.org/en/guidelines].

8 .- SILVA PÉREZ, R. y FERNÁNDEZ SALINAS, V., "El nuevo paradigma del patrimonio...", op.cit. 
administración de cultura y que ahora se hace muy ostensible ante la magnitud y complejidad de los desafíos planteados por la protección de los territorios.

Ambas situaciones, que están íntimamente relacionadas, están provocando un efecto realmente pernicioso no sólo para la protección de los paisajes culturales sino para la tutela del patrimonio cultural en general. Nos referimos al hecho de que cada vez se está poniendo más en cuestión (invalidando, por tanto) la viabilidad de la aplicación a los paisajes culturales de los mecanismos generales de tutela del patrimonio cultural, lo cual está propiciando que se arbitren instrumentos específicos, excepcionales o propios de otros ordenamientos jurídicos para abordar la actuación en estos ámbitos patrimoniales. Tanto desde el ámbito propiamente paisajístico, demandando que los paisajes culturales se integren en los mecanismos generales de actuación (protección, gestión e intervención según la terminología del Convenio Europeo del Paisaje) en el paisaje (para lo que se están promulgando leyes específicas al respecto, tal y como antes señalábamos), y que nos remiten principalmente a los instrumentos de planificación, como desde el ámbito patrimonial, donde la protección de los paisajes culturales se entiende en la mayoría de los casos como una iniciativa excepcional que requiere de medios y procedimientos igualmente excepcionales, por lo tanto ajenos o diferenciados de la acción ordinaria de la administración patrimonial. El muy relevante ejemplo de la promulgación de una ley específica para la protección de la Huerta de Valencia ${ }^{9}$ (y que fue consecuencia del fracaso, muy ilustrativo, por cierto, de lo que estamos contando, de una anterior propuesta de declaración de $\mathrm{BIC}^{10}$ ), que, en principio, podríamos considerar como una gran conquista, sobre todo de la sociedad civil, en defensa de este excepcional espacio agrario histórico, no podemos más que calificarla como la constatación del fracaso del patrimonio cultural (del sistema de tutela del patrimonio cultural) para abordar la protección de los paisajes culturales y, en definitiva, de los territorios. La absoluta e indiscutible relevancia cultural de la Huerta de Valencia exigiría que de forma igualmente indiscutible fuera ésta, su condición cultural, de patrimonio cultural, la que propiciara y determinara todo el sistema de actuación en la misma, incluida, la activación agraria.

Este optar por externalizar (aceptada incluso desde el ámbito patrimonial) la actuación en los paisajes culturales en vez de reclamar un rearme o reforzamiento

9 .- Ley 5/2018, de 6 de marzo, de la Huerta de València.

10 .- Esta solicitud, presentada en febrero de 2005 por Ecologistas en Acción y la Sociedad Española de Agricultura Ecológica, aunque promovida por la asociación Per L'Horta, terminaría con una resolución del Tribunal Superior de Justicia de Valencia en enero de 2007 negando la posibilidad de declarar BIC la Huerta de Valencia con los argumentos tan discutibles como la enorme amplitud y complejidad del espacio susceptible de protección. 
de la administración tutelar ante los enormes retos que está planteando la protección de los territorios, lo que está provocando, incidiendo en los importantes peligros de los que antes advertíamos, es la desacreditación (y deslegitimación, por tanto) del sistema tutelar vigente, lo que está llevando a reclamar desde el ámbito del paisaje una especie de reformulación o refundación paisajística del patrimonio cultural, ya iniciada, por ejemplo, en el ámbito de las ciudades históricas, las cuáles pretenden ser sustituidas (en cuanto a su reconocimiento y actuación patrimonial) por el concepto de paisaje urbano histórico; aspiración ésta que consideramos totalmente improcedente e ilegítima tal y como creemos haber demostrado con gran claridad (y contundencia) en otro lugar ${ }^{11}$.

Ante esta situación, que lo que pone de manifiesto es la enorme confusión y dudas en relación al alcance de la figura de los paisajes culturales y a los procedimientos y objetivos para abordar su protección, nuestro posicionamiento al respecto es muy claro: consideramos que el paisaje cultural debería ser exclusivamente una tipología de bien inmueble reconocida por la legislación de patrimonio cultural ${ }^{12}$. Ésta se aplicaría sobre aquellos espacios de carácter territorial (donde la dimensión urbana, que puede estar presente, no sea la predominante) que tengan un componente patrimonial diverso, complejo y diacrónico, lo que reclamaría una identificación de la misma desde la unidad del territorio en la que de forma interrelacionada se manifiestan todos los elementos que la constituyen, de ahí la posibilidad de utilizar la topografía, la orografía, el relieve, el territorio en definitiva como elemento definidor (Fig. 2) ${ }^{13}$. Esto significa que el sistema de protección aplicable a los paisajes culturales debería ser el propio de los bienes culturales, en concreto el de los bienes inmuebles, el cual consideramos está perfectamente dotado para conseguir una adecuada tutela (declaración, régimen de protección, difusión, gestión, intervención, participación pública, etc.) de los mismos. De esta forma la figura de paisaje cultural, como ya señalábamos en otro lugar, "debería funcionar como un instrumento preciso, incisivo, permanente, integral, integrador, superior y dominante respecto a la organización, ordenación y desarrollo de un territorio signado con

11 .- CASTILLO RUIZ, J., "El patrimonio cultural podría estar en peligro y los responsables son la memoria, la salvaguardia, la comunidad y el paisaje cultural (además del turismo, claro)", erph revista electrónica de patrimonio histórico, $\mathrm{n}^{\circ}$ 28, 2021, pp. 3-38. https://doi.org/10.30827/erph.vi28.21530.

12 .- También creemos que se podría considerar al valor paisajístico como uno de los valores reconocidos por la legislación al igual que otros ya instituidos como el artístico, arqueológico o etnológico, el cual podría aplicarse a tipos de bienes, especialmente los de carácter urbano y territorial, en concurrencia con el resto de valores, y entendido desde una perspectiva más puramente perceptiva y estética.

13 .- Un ejemplo muy interesante de la aplicación de esta figura es la declaración en 2017 del Valle del Darro en Granada como BIC bajo la tipología de Zona Patrimonial (figura equivalente a la de paisaje cultural) en la cual se ha tomado como referencia para la delimitación del bien el valle generado por el río Darro y sus afluentes desde su nacimiento hasta su desembocadura en la ciudad de Granada. 
valores cultures y digno de protección. Un instrumento que sirva para someter todos los procesos urbanos y territoriales al dictamen de la prevalencia de los valores culturales existente en el territorio, cuya preservación y continuidad en absoluto puede observarse como freno al desarrollo socio-económico de ese territorio. Este instrumento debe tener la capacidad de paralizar todos los planes, programas e instrumentos de ese paisaje protegido para a partir de su revisión, validar su viabilidad como idóneo instrumento de protección. En definitiva, nada diferente a como se opera en el campo de los conjuntos históricos o de cualquier otro bien cultural de carácter inmueble. "14 Todo esto, todos estos efectos, son los que se derivan de la declaración de un determinado territorio como BIC bajo la categoría de paisaje cultural o figura similar y que no pueden ser suplantados, diluidos o subordinados por todos estos sucedáneos de protección como son los catálogos o inventarios de paisajes y, con ellos, los diferentes instrumentos de planificación u ordenación territorial puestos en marcha de forma independiente y ajena a la administración cultural.

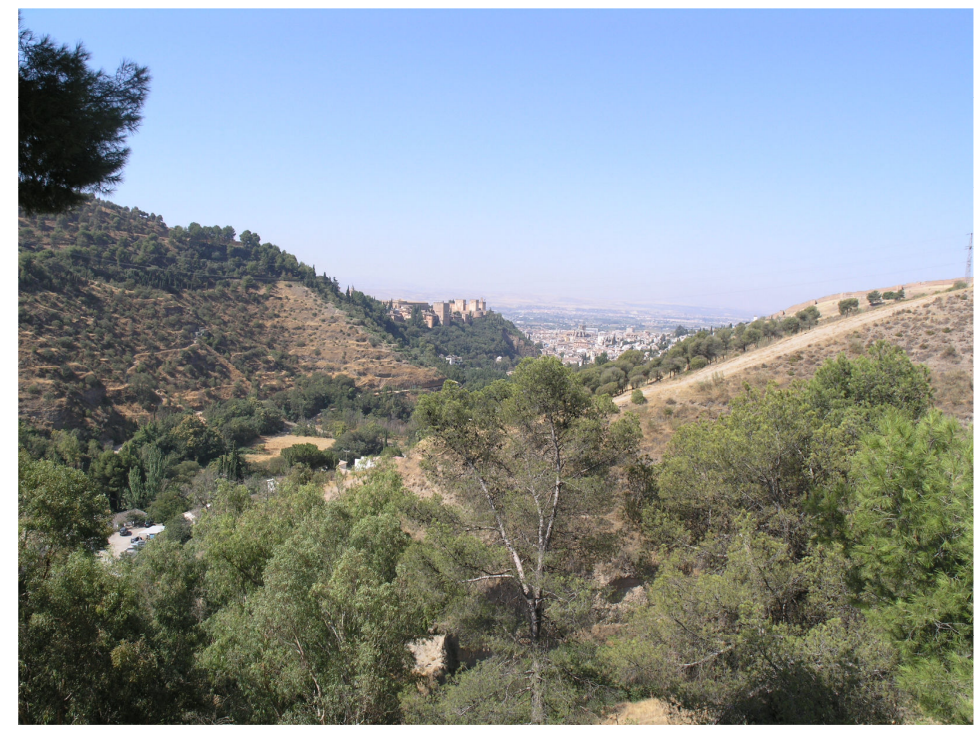

Fig. 2.- Valle del Darro en las inmediaciones de la Alhambra y el Albayzin (Granada). (C) José Castillo Ruiz.

14 .- CASTILLO RUIZ, J., "La "bictitis” o la alergia social (¿o es sólo política?) a la protección de los bienes culturales de carácter territorial. reflexiones y propuestas a partir del caso de la Vega de Granada", en CASTILLO MENA, A. (ed.), Personas y comunidades: Actas del Segundo Congreso Internacional de Buenas Prácticas en Patrimonio Mundial: (29 -30 de abril, 1 y 2 de mayo de 2015), Madrid, Universidad Complutense de Madrid, Servicio de Publicaciones, Madrid, 2015, p. 420. http://eprints.ucm.es/34899/. 


\section{2.- EL PATRIMONIO AGRARIO COMO PRINCIPAL MARCO DE RE- FERENCIA PARA LA PROTECCIÓN DE LOS PAISAJES CULTURA- LES: PRINCIPIOS FUNDAMENTALES.}

Determinada la validez de la figura del paisaje cultural (en los términos señalados) y de la idoneidad del sistema de protección instituido para ella en la legislación de patrimonio cultural, lo que nos corresponde ahora analizar es si este sistema es igualmente válido para la protección de los espacios agrarios y, por tanto, de la actividad agraria que los propicia.

Aunque, tal y como antes señalamos, son pocos los paisajes culturales declarados (y esos son, deben ser, los que vamos a tomar como referencia) debemos concluir que en la mayoría de los casos la componente agraria resulta muy importante o determinante, hecho éste absolutamente lógico si tenemos en cuenta la coincidente dimensión territorial (e incluso podríamos decir que rural) de los paisajes culturales y de los bienes agrarios. Esto es especialmente perceptible si analizamos el conjunto de paisajes culturales reconocidos por la UNESCO como Patrimonio Mundial, que es la figura equivalente (y la que se toma como referente) a la reconocida por nuestra legislación, y donde los paisajes cuyo valor universal excepcional está directamente asociado a la actividad agraria se acerca a la mitad de los inscritos ${ }^{15}$. De aquí se podría deducir que la figura más idónea para proteger los bienes agrarios sería ésta del paisaje cultural. Es más, pareciera que sólo es posible hacerlo desde esta figura dada, insistimos, la imprescindible dimensión territorial de lo agrario.

Llegados a este punto debemos manifestar una premisa (otra más) que sustenta este trabajo: en la actualidad si bien existe un reconocimiento patrimonial de numerosos bienes agrarios (cortijos, haciendas, hórreos, palomares, terrazas de cultivo, asentamientos rurales, técnica constructiva de piedra seca, acequias y canales, formas de gestión de los sistemas históricos de riego, etc.) éstos, en la mayoría de los casos, lo están en función no de su valor o naturaleza agraria sino de otros valores de tipo artístico, histórico, técnico, rural, industrial, etc., lo cual acaba afectando a la adecuada protección de los mismos ya que terminan otorgándole una valoración subordinada, derivada, cuando no exenta de su indispensable dimensión funcional dinámica e innovadora. Sucede con la identificación (más bien absorción) de los bienes agrarios con el patrimonio rural (lo que limita el reconocimiento de la importante agricultura urbana y periurbana),

15 .- Ver al respecto MARTÍNEZ YÁÑEZ, C. "El Patrimonio Agrario inscrito en la Lista del Patrimonio Mundial: Tipos de bienes, modelos de gestión y desafíos", en CASTILLO RUIZ, J. y MARTÍNEZ YÁÑEZ, C. (coord.), El Patrimonio Agrario. La construcción cultural del territorio a través de la actividad agraria, Sevilla, UNIA, 2015, pp.183-229. 
con el patrimonio etnológico (lo que excluye toda la actividad agraria promovida o desarrollada en ámbitos institucionales u oficiales como palacios, monasterios, etc.) o con el patrimonio industrial (donde los espacios agrarios acaban adquiriendo el secundario, y muchas veces prescindible en cuanto a su protección concreta papel de simples suministradores de las materias primas utilizadas por las fábricas) (Fig. 3).

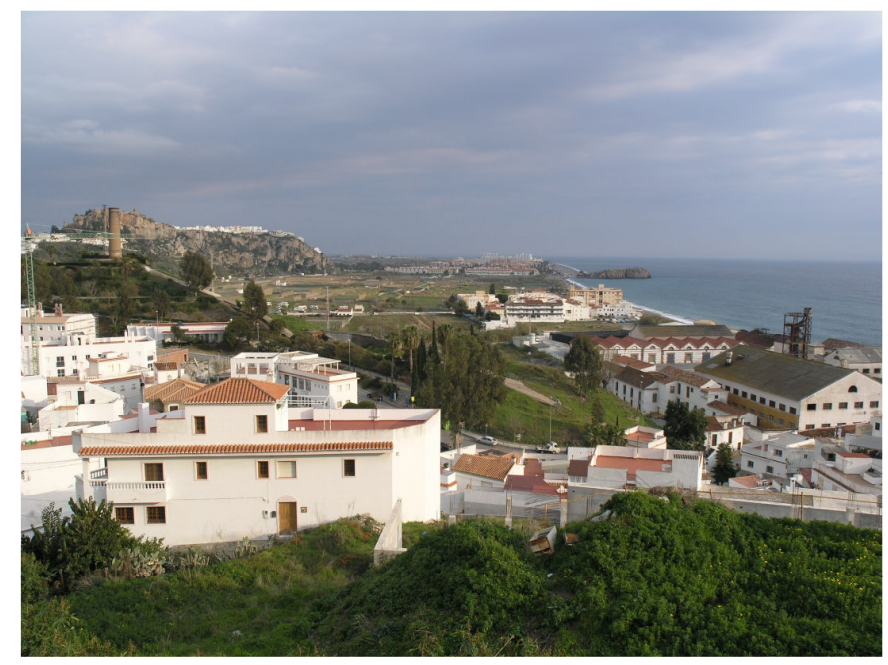

Fig. 3.- Paisaje de Salobreña con la Azucarera del Guadalfeo a la derecha. (C) José Castillo Ruiz.

Esta constatación es especialmente evidente en el caso de los paisajes culturales, ya que si analizamos la mayoría de los declarados (aquí es muy importante tomar como referencia los reconocidos por la UNESCO) ${ }^{16}$ nos encontramos que a pesar de tratarse de indiscutibles paisajes de componente agraria, la actividad agrícola o ganadera queda efectivamente relegada, suplantada, subordinada, ocultada por otros valores o componentes como el industrial o el productivo (de ahí el predominio de paisajes vinculados a productos elaborados o extraídos del cultivo laboreado en ese espacio agrario, tal y como sucede especialmente con el vino -con numerosas declaraciones como la Jurisdicción de

16 .- El estudio de los bienes reconocidos por la UNESCO tanto desde la perspectiva del Patrimonio Mundial como del Patrimonio Cultural Inmaterial y su relación con el Patrimonio Agrario ha sido realizado magistralmente por la profesora Celia Martínez Yáñez: MARTÍNEZ YÁÑEZ, C. "El Patrimonio Agrario inscrito en la Lista del Patrimonio Mundial..., op. cit., y MARTÍNEZ YÁÑEZ, C. "Los paisajes agroindustriales en la Lista del Patrimonio Mundial. Agricultura versus Industria", en CASTILLO RUIZ, J. y ROMERO GALLARDO, A. (coord..). Patrimonio cultural, remolacha y nuevas tecnologías. El paisaje agroindustrial de la remolacha en la Vega de Granada a partir de la reconstrucción en $3 D$ de la Fábrica de Nuestro Señor de la Salud de Santa Fe, Granada, Universidad, 2019, pp. 37-58. 
Saint Emilion, Francia, 1999; los Viñedos, Casas y Bodegas de Champaña, Francia, 2015; la Región vinícola del Alto Duero, Portugal, 2001; las Terrazas de Viñedos de Lavaux, Suiza, 2007 (Fig. 4), etc.-, pero también con otros productos como el tequila -el Paisaje de Agaves y Antiguas Instalaciones Industriales de Tequila, México, 2006- o el café -el Paisaje Cultural Cafetero, Colombia, 2011-), el natural (de ahí la preferencia por aquellos paisajes más naturalizados, es decir, donde la similitud con los paisajes naturales es mayor por la presencia de elementos arbóreos o arbustivos de cierto porte como viñas, cafetales, olivos o palmeras y que, además, le dan al paisaje un carácter de permanencia y continuidad en el tiempo; de ahí también la preferencia por los paisajes agrarios de montaña donde la actividad agraria está muy imbricada con los elementos naturales -aquí se podrían añadir a los citados en el apartado anterior el Valle del Madriu-Perafita-Claror, Andorra, 2006 y el Paisaje Cultural Agropastoral Mediterráneo de Causses y Cévennes, Francia, 2011), o el estético y monumental (de ahí el reconocimiento a aquellos paisajes donde esta dimensión estética es más evidente como es el caso de los "espectaculares" paisajes aterrazados de arrozales de la región Asia-Pacífico -El Paisaje Cultural de los Campos de Arrozales en Terrazas de las Cordilleras de Luzón Central, Filipinas, 1995; el Paisaje Cultural de la Provincia de Bali: el Sistema Subak como testimonio de la Filosofía Tri Hita Karana, Indonesia, 2012 o el Paisaje Cultural de las Terrazas de Arrozales de Honghe Hani, China, 2013- o el de aquellos que generan formas y colores muy atractivos y reconocibles socialmente -El Valle del Orcia, Italia, 2004-).

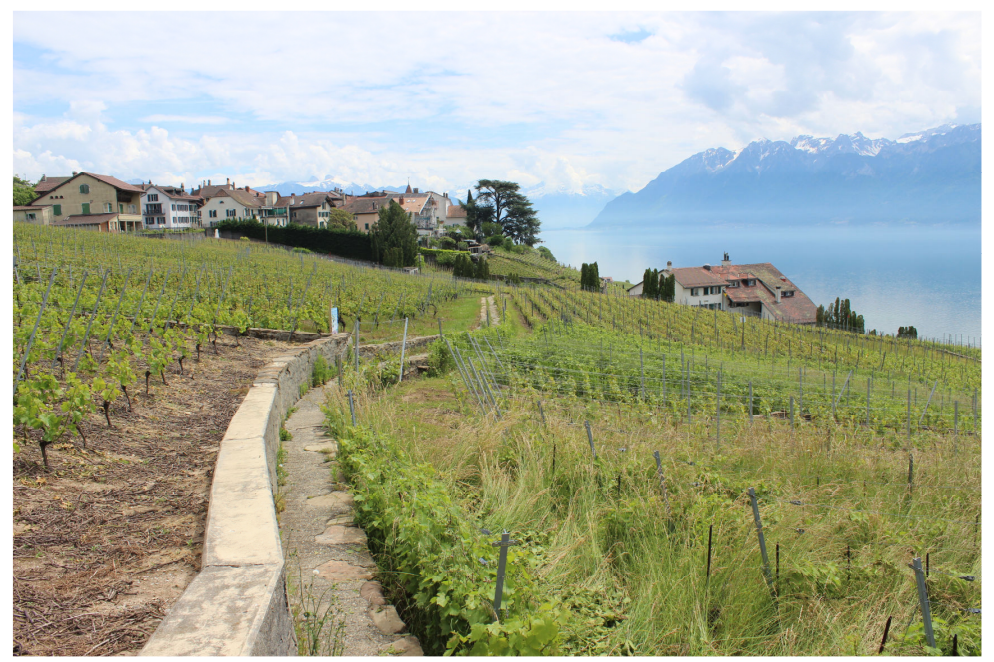

Fig. 4.- Viñedos de Lavaux (Suiza). @ José Castillo Ruiz. 
Para afrontar entonces un adecuado reconocimiento de la dimensión agraria desde la perspectiva de los paisajes culturales (la cual es sólo un instrumento más de los diversos que existen para proteger este patrimonio) debemos acudir al concepto de Patrimonio Agrario, en el cual quedan establecidos los fundamentos, objetivos e instrumentos desde los que abordar la caracterización y actuación sobre cualquier bien agrario, especialmente el de los paisajes culturales agrarios. Nuestro protagonismo en la configuración del marco conceptual del Patrimonio Agrario en cuanto director del amplio equipo de investigación que elaboró, entre muchas otras aportaciones, la Carta de Baeza sobre el Patrimonio Agrario $^{17}$, que es el documento de referencia principal para este concepto, nos permite, nos legitima para ello, exponer con cierta amplitud los principios en los que se sustenta este nuevo tipo de patrimonio cultural y que debemos tomar como referencia para el reconocimiento y actuación sobre los paisajes culturales agrarios. Éstos son los principios fundamentales del Patrimonio Agrario:

- Aunque debe reconocerse el valor agrario como valor general para la identificación de este tipo de bienes (y como concreción del mismo, los valores agronómico, económico, social, ecológico, histórico, paisajístico y técnico) el principal valor que debe sustentar el concepto de Patrimonio Agrario debe ser el valor cultural, lo que supone entender la actividad agraria como una práctica social y económica de indudable y crucial aportación a la civilización humana. De ahí la absoluta legitimidad y necesidad de que lo agrario, los bienes agrarios, sean considerados como parte del patrimonio cultural. A partir del reconocimiento de estos valores la definición que se aporta es la siguiente: "El Patrimonio Agrario está conformado por el conjunto de bienes naturales y culturales, materiales e inmateriales, generados o aprovechados por la actividad agraria a lo largo de la historia" ${ }^{18}$

- La actividad como elemento constitutivo principal. El elemento fundamental que propicia y justifica el reconocimiento del patrimonio agrario es la actividad agrícola, ganadera y silvícola, lo cual impone una exigencia ineludible para su protección: el mantenimiento in situ de la actividad agraria en los bienes o espacios protegidos como garantía de su preservación y continuidad futura.

- La protección de los bienes culturales agrarios debe hacerse necesariamente desde el patrimonio cultural, en cuanto parte indiscutible del

17 .- CASTILlO RUIZ, J. (dir.), La Carta de Baeza sobre Patrimonio Agrario, Sevilla, UNIA, 2013. http://hdl.handle.net/10481/36377.

18 .- Ibid, p. 32. 
mismo, por lo que no deberían utilizarse mecanismos excepcionales (como leyes específicas para la protección de algún bien o conjunto de ellos, caso de la ya señalada Ley de la Huerta de Valencia de 2018 o la Ley del Olivar de Andalucía de 2011) o abordajes desde otros ámbitos no estrictamente patrimoniales como, por ejemplo, los SIPAM (Sistemas Ingeniosos del Patrimonio Agrícola Mundial), (Fig. 5) que es la figura equivalente a la de Patrimonio Mundial utilizada por la FAO para reconocer los valores de los sistemas agrarios tradicionales. Aunque existen en el ámbito del patrimonio cultural diferentes mecanismos para proteger los bienes integrantes del patrimonio agrario, los principales deben ser aquellos de carácter territorial, de ahí la necesidad de utilizar alguna de las tipologías de bien de conjunto previstas en la legislación para su declaración: zona patrimonial, sitio histórico y, muy especialmente, la de paisaje cultural (desde la Carta de Baeza se propone, no obstante, que se establezca una tipología específica para los espacios agrarios que es la de Lugar de Interés Agrario). La aplicación de estas tipologías permite además utilizar los instrumentos urbanísticos y territoriales como principal mecanismo de actuación en los mismos.

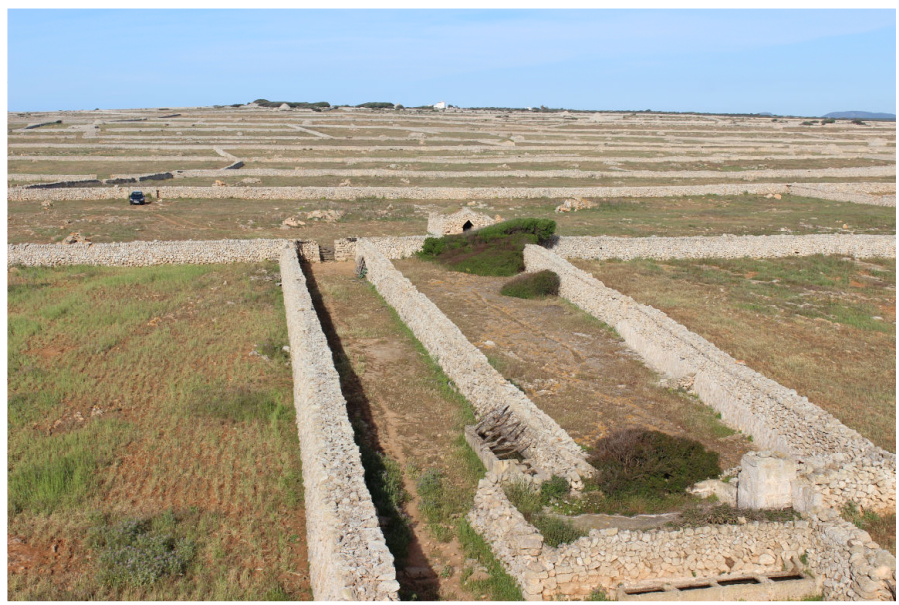

Fig. 5.- Instalaciones ganaderas en Punta Nati (Ciudadela, Menorca).

(C) José Castillo Ruiz.

- La singularidad del Patrimonio Agrario exige además que el mecanismo de protección que se instaure incorpore un sistema (y organismo) de gestión de carácter territorial, supramunicipal e interadministrativo que pueda afrontar, además de la protección directa los bienes 
declarados, todas las políticas necesarias para el mantenimiento y desarrollo de la actividad agraria (y todas aquellas otras que sean compatibles) en el espacio protegido. No obstante, no es admisible la idea muy extendida de que un espacio agrario se protegerá sólo cuando sea rentable económicamente, es decir sólo con gestión.

De estos presupuestos es quizás la consideración de la actividad agraria (agrícola, ganadera y silvícola) como el elemento constitutivo del patrimonio agrario el aspecto más complejo (y controvertido) de abordar, sobre todo, porque existe una errónea percepción de que la declaración de un determinado bien como patrimonio cultural (especialmente como BIC), con la consiguiente imposición del régimen jurídico derivado de la misma, constituye la fosilización, musealización o momificación del bien objeto de protección, lo cual invalidaría cualquier iniciativa de patrimonialización de lo agrario dada la inexcusable consideración de la actividad agraria (su mantenimiento o activación) en cualquier acción sobre estos bienes.

En este sentido debemos señalar, más bien subrayar, que la tutela del patrimonio histórico ya tiene plenamente incorporada la dimensión funcional entre sus principios y mecanismos de actuación. Esto es especialmente constatable en los conjuntos históricos, donde el mantenimiento de la diversidad funcional urbana (vivienda, servicios públicos, tiendas, hoteles...) es una exigencia ineludible en cualquier política de protección desde la instauración del concepto de conservación integrada en la Carta de Patrimonio Arquitectónico de 1975. La calificación de usos a través de los instrumentos urbanísticos, al margen de todas las acciones, medidas y políticas de fomento de la rehabilitación y usos de los centros históricos, es el instrumento principal utilizado para ordenar las funciones de estos espacios urbanos históricos y su respetuosa adecuación a los valores culturales de los mismos. Esto significa que el procedimiento instaurado consiste en remitir al ámbito (normativo y administrativo) correspondiente, en este caso el urbanístico, la responsabilidad y competencia para regular y preservar la dimensión funcional de estos espacios; procedimiento éste que sería perfectamente aplicable a cualquier otro espacio, como por ejemplo el agrario, donde la administración agrícola y ganadera, con sus instrumentos y mecanismos, tendría la responsabilidad, con la autorización general y genérica de la administración de cultura, de actuar en estos espacios agrarios.

Al igual que resultaría absurdo amenazar a un comerciante de un centro histórico diciéndole que tendrá que someter a la discrecional autorización de la administración de cultura el género (lencería, perfumería, telefonía, carnicería...) que quiera vender en su tienda, lo es también cuando se quiere intimidar 
a los agricultores y ganaderos magnificando y distorsionando las restricciones que supondría para el desarrollo de su actividad la declaración de su propiedad como patrimonio cultural, hecho éste que desgraciadamente se produce a menudo (y que nosotros hemos contemplado numerosas veces en el complejo proceso de reclamación ciudadana de la declaración de la Vega de Granada como BIC, Zona Patrimonial) ${ }^{19}$ y que tiene que ver (además de con la pésima imagen social de la administración de cultura) con la desconsideración y minusvaloración de la actividad agraria (que es extensible al campo y campesinos) frente a otras como la urbana.

\section{3.- LOS PAISAJES CULTURALES AGRARIOS: ÁMBITO DE APLICA- CIÓN Y CRITERIOS PARA SU DELIMITACIÓN Y PROTECCIÓN.}

Determinada (y creemos que justificada) la condición del paisaje cultural como una tipología de bien cultural muy acorde para el reconocimiento y protección de los bienes agrarios (para aquellos que disponen de una dimensión territorial, que siendo la predominante no es la única), las cuestiones que quedarían por abordar serían fundamentalmente dos: la de cómo proceder a la delimitación (a su caracterización en suma, pues son condiciones inseparables dada la condición formal del patrimonio cultural) de ese paisaje cultural y la de qué tipo de instrumentos y medidas deberían utilizarse para su protección.

Realmente nos vamos a centrar en la cuestión de la delimitación, porque lo referido a los instrumentos de protección no ofrece para nosotros muchas dudas, ya que, como antes decíamos, el sistema tutelar imperante en nuestro ordenamiento jurídico está perfectamente preparado para abordar la actuación en los bienes territoriales, el cual podríamos identificarlo con el ya legendario concepto de conservación integrada, que no es más que la interrelación de todos los instrumentos de ordenación y desarrollo de un determinado territorio, siempre a partir de la prevalencia (y superioridad jerárquica desde el punto legal) del sistema de protección patrimonial; prevalencia ésta activada (y amparada) por la declaración, especialmente como BIC, del espacio agrario a proteger. Un sistema de tutela al que habría que incorporar aquellas exigencias propias del concepto de Patrimonio Agrario antes vistas como es la importancia de los organismos e instrumentos de gestión y la centralidad de la conservación y mantenimiento de la actividad agraria.

19 .- CASTILLO RUIZ, J., “La “bictitis” o la alergia social (¿o es sólo política?)..., op. cit. 
Centrados, entonces, en la cuestión de la delimitación, lo primero que cabría señalar es la dificultad para proceder a la misma, situación ésta común a todos los paisajes culturales, de ahí que en la mayoría de propuestas provenientes del ámbito paisajístico no se haya descendido hasta esta cuestión, limitándose a establecer criterios a partir de los cuales poder identificar y caracterizar los diferentes tipos o subtipos de paisajes existentes (las unidades de paisaje, según esta metodología) en una determinada región o comunidad autónoma ${ }^{20}$. No es de extrañar entonces las reticencias existentes en el campo paisajístico para someterse a la precisión y concreción de las declaraciones de patrimonio cultural, las cuales necesariamente tienen que tener unos límites muy precisos; límites éstos que no sólo demarcan la extensión del espacio objeto de protección sino también, y esto muy especialmente, los márgenes competenciales (su capacidad de actuación, en suma) de cada uno de los ámbitos administrativos y legales (urbanismo, infraestructuras, medio ambiente, etc.) concurrentes en el mismo.

En el caso de los paisajes culturales agrarios esta dificultad para proceder a su delimitación viene motivada obviamente por las características de la propia implantación territorial de la actividad agraria, donde podemos destacar las siguientes particularidades:

- La confusa (o directamente inexistente) diferenciación entre aquellas actividades o espacios agrarios dotados de valor cultural $\mathrm{y}$, por tanto, susceptibles de protección, y aquellos otros que, cumpliendo las mismas funciones productivas, alimenticias o incluso medioambientales (como por ejemplo la agricultura ecológica), no merezcan esa consideración. Esta confusión hace que el simple planteamiento de la protección de los paisajes agrarios aparezca como una empresa inabordable e irrealizable al identificarse éstos con el conjunto de la actividad agraria de una comarca, región o incluso país. En este sentido, como luego veremos, resulta fundamental, y previo a cualquier iniciativa patrimonial, identificar los criterios que deben cumplir cualquier bien agrario para poder ser considerado como patrimonio cultural ${ }^{21}$.

20 .- Este es el proceder de los diferente trabajos de estudio y catalogación de los paisajes culturales puestos en marcha en las diferentes comunidades autónomas y citados en la nota 3.

21 .- Un ejemplo de esta falta de diferenciación entre los espacios agrarios dotados de valor cultural y aquellos otros carentes del mismo es el, por otro lado magnífico y monumental, trabajo de caracterización de todos los paisajes agrarios en España liderado por el geógrafo Fernando Molinero (MOLINERO, F (coord.), Atlas de los Paisajes Agrarios de España. Tomo I. Las clases de paisajes agrarios de España. Las unidades de paisaje agrario de la España atlántica, Madrid, Ministerio de Agricultura, Alimentación y Medio Ambiente, 2013 y MOLINERO, F (coord.), Atlas de los Paisajes Agrarios de España. Tomo II. 
- La enorme amplitud y dispersión de la actividad agraria por el territorio, por cualquier territorio, sobre todo en el caso de la agricultura de secano (las campiñas cerealistas, por ejemplo) o la de aquella que no depende de los rígidos sistemas históricos de riego por existir una abundante pluviosidad. Lo mismo se podría decir del singular sistema agrario de las dehesas, de la explotación forestal, de los pastizales o de la actividad ganadera extensiva, especialmente la trashumancia. Dispersión y fragmentación que hace enormemente difícil poder identificar de forma unitaria (aunque sea con un carácter discontinúo) un territorio al que poder formalizar, poder declarar, como paisaje cultural, dado lo difuso, extenso, fragmentado, discontinuo, a la vez que interrelacionado, de la implantación y desarrollo de la actividad agraria.

- La variabilidad de los espacios agrarios en función de la explotación o no (temporal o definitiva) de los mismos. Variabilidad que no deberíamos confundir con la existencia o no se uso agrario, ya que un espacio abandonado que mantiene toda la estructura para poder activarlo (acequias, bancales, caminos, etc.) no podemos excluirlo de una posible patrimonialización porque en un momento puntual determinado esté en desuso. (Fig. 6)

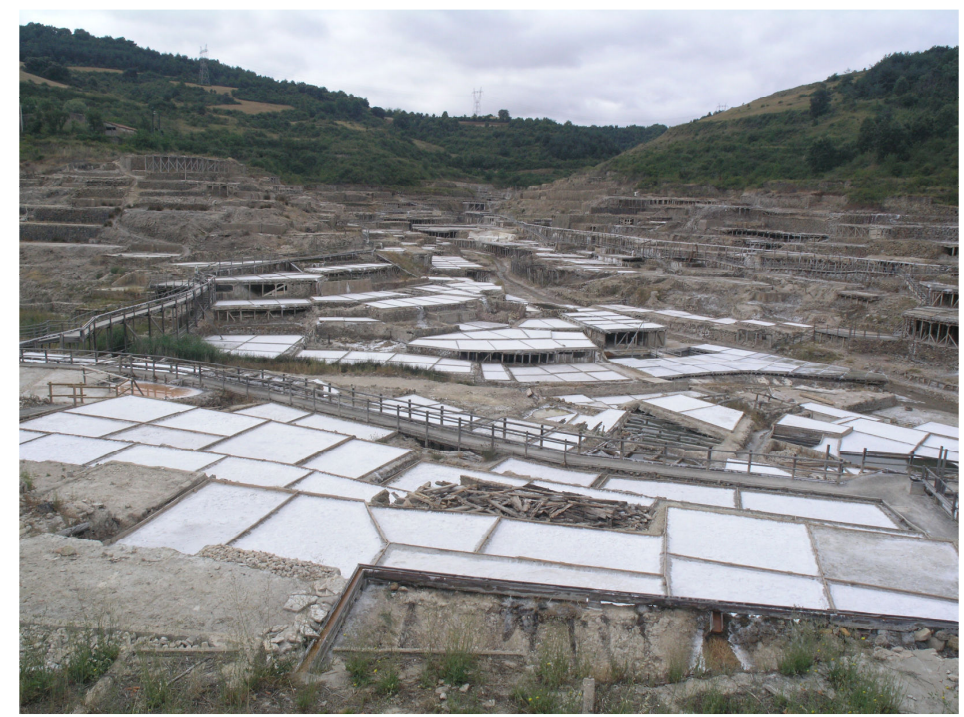

Fig. 6.- Valle Salado de Añana (Vitoria). C José Castillo Ruiz.

Las unidades de paisaje agrario de la España mediterránea, Madrid, Ministerio de Agricultura, Alimentación y Medio Ambiente, 2014). 
- La interrelación con otras actividades y funciones y, por lo tanto, con otros patrimonios, lo cual dificulta la identificación de un determinado espacio en función de dicha actividad. Es esta la razón por la cual los bienes agrarios han sido observados o bien desde la perspectiva rural (que sitúa en el tipo de medio ocupado por el hombre el ámbito a identificar) o bien desde un enfoque territorial más amplio (la globalidad de un determinado territorio, de un paisaje), lo cual, en ambos casos, acaban diluyendo y difuminando la presencia de lo agrario.

Teniendo en cuenta todas estas particularidades, los criterios a seguir para identificar y delimitar un determinado espacio agrario como paisaje cultural deberían ser los siguientes:

- El paisaje cultural es una tipología de bien inmueble a utilizar para reconocer aquellos espacios o ámbitos de carácter territorial donde se desarrolla una actividad agraria de relevantes valores culturales y que, por tanto, merece su protección. De aquí se deriva que debe ser necesariamente la actividad agraria el elemento determinante en la constitución de dicho paisaje, ya que de lo que se trata no es de proteger un determinado territorio sino una actividad agraria en su implantación territorial. En este sentido debemos tener presente la multidimensionalidad de lo agrario ${ }^{22}$, ya que se trata de un actividad que no sólo tiene implicaciones ambientales, económicas, biológicas, tecnológicas, hidráulicas, sociales, sino que como actividad primaria dispone de una enorme capacidad para generar otros productos, conocimientos y actividades culturales más complejas, como por ejemplo todo lo referido a la manipulación, conservación o comercialización de los alimentos; en definitiva, manifiesta una gran capacidad para generar otros patrimonios.

Por eso es importante fijar el límite sobre aquello que es propiamente agrario y qué pertenece ya a otra actividad $\mathrm{y}$, por tanto, a otro patrimonio. El límite debe estar fijado en aquella actividad, producto u objeto que es realizado o creado por el agricultor (en sentido amplio de persona que realiza la actividad agraria) como parte del proceso productivo agrario. Cuando esta actividad, aunque proceda de un cultivo (la fibra del cáñamo, por ejemplo), se realice de forma independiente y

22 .- Preferimos este concepto, a pesar de su cercanía, al de la multifuncionalidad agraria que es el instituido en el ámbito académico geográfico o agrícola. Ver al respecto GÓMEZ-LIMÓN RODRÍGUEZ, J. A. BARREIRO HURLÉ, J., MÁRMOL, E. y MARCOS, C. (coord.), La multifuncionalidad de la agricultura en España. Concepto, aspectos horizontales, cuantificación y casos prácticos, Madrid, Ministerio de Agricultura, Alimentación y Medio Ambiente, 2007. 
autónoma, sea de forma artesanal o mecanizada, los elementos patrimoniales generados por esa actividad ya no podrán considerarse patrimonio agrario. Por ejemplo: el secado del tabaco que se realiza en un secadero construido en la parcela o en el territorio donde éste se cultiva, aunque pudiera considerarse como el inicio del proceso industrial de elaboración del tabaco, realmente forma parte de la actividad agraria, en este caso como labor correspondiente a la recogida y almacenamiento del cultivo previo a su comercialización o manipulación futura. En este caso sí debe ser considerado como patrimonio agrario. (Fig. 7). En cambio, un artesano que realice alpargatas de cáñamo, aunque las haga en el mismo territorio donde se cultiva el cáñamo, será un artesano y formará parte del patrimonio etnológico o inmaterial de la zona. La clave del patrimonio agrario debe ser, por tanto, la existencia de una continuidad (de tipo laboral, personal-familiar, social, territorial, económica) directa y necesaria entre todas las fases del proceso productivo: desde la preparación de la tierra o el ganado hasta la elaboración del producto o creación de la actividad objeto de protección.

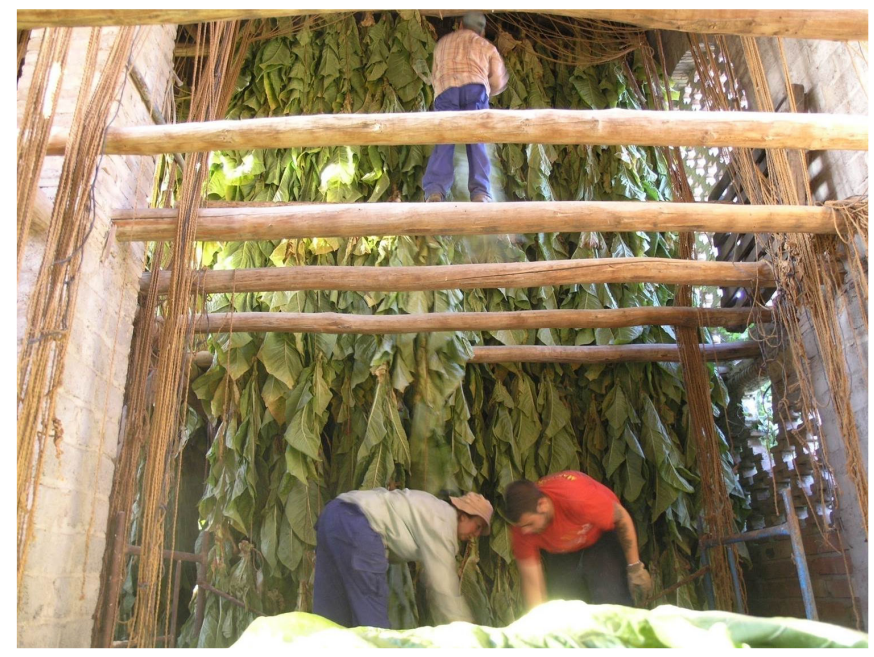

Fig. 7.- Colgando tabaco en el secadero del Caserío Checa (Granada).

(C) José Castillo Ruiz.

- Aunque, como decíamos antes, desde el Patrimonio Agrario se reconoce el valor agrario como valor general para la identificación de este tipo de bienes, el principal valor que debe sustentar este patrimonio es el valor cultural. Un valor cultural, y esto resulta de una gran importancia, que debe observarse (al igual que el resto de valores reconocidos 
en la legislación de patrimonio cultural como el artístico, el industrial o el científico) desde una dimensión histórica y/o tradicional, ya que la práctica agraria a preservar es aquella que, fundada en prácticas tradicionales de manejo sustentables, se ve amenazada en la actualidad, entre otras causas, por la agricultura intensiva e industrializada.

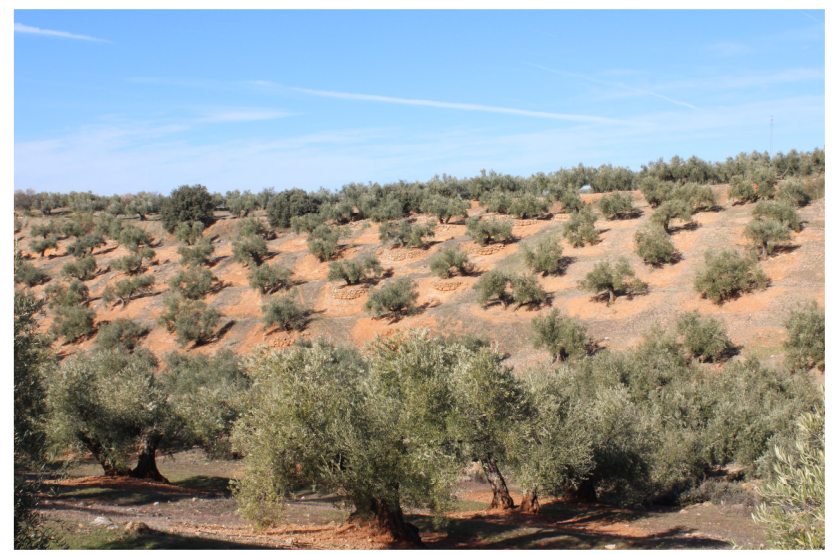

Fig. 8.- Olivos en la zona de Sierra Mágina (Jaén). José Castillo Ruiz.

Es desde esta condición histórica (y sólo desde ella) desde la que podemos establecer unos criterios que permitan diferenciar (y justificar) qué espacios, qué olivares, si tomamos, por ejemplo, los paisajes del olivar de Andalucía (que en la actualidad están siendo objeto de estudio para su posible inclusión en la Lista de Patrimonio Mundial ${ }^{23}$ ), (Fig.8) podemos considerar como susceptibles de protección, ya que, siguiendo con este caso del olivar, no es posible identificarlos ni en función de la actividad (pues todos los olivos, desde los milenarios a los recién plantados, producen aceituna, incluso puede que sea de la misma variedad), ni de las propiedades alimenticias, culinarias o de salud (pues esto es común a la aceituna, es decir a todos los olivares), ni siquiera por las cualidades ambientales del mismo, ya que en ese caso cualquier olivar ecológico recién plantado recibiría la condición de patrimonio cultural, hecho éste que sería como equiparar el valor cultural de las casas nazaríes del Albaicín con los de una casa de nueva construcción en cualquier barrio de la periferia de Granada realizada con materiales reciclados y climatizada con energía renovables ${ }^{24}$. Por lo

23 .- https://www.paisajesdelolivar.es/candidatura/\#expediente. [Consulta 30/06/2021].

24 .- Hay que hacer una importante distinción entre prácticas agrícolas actuales saludables o respetuosas con el medio, como puede ser la agricultura ecológica, y el Patrimonio Agrario. Aquí hay que 
tanto, y siguiendo con este caso del olivar, el criterio fundamental para identificar qué conjuntos de olivares (dado el carácter de paisaje seriado utilizado en la candidatura) deberían incluirse en dicha declaración sería el de la antigüedad (y continuidad histórica) de la implantación de los olivos objeto de declaración (y de protección, se supone, por tanto), la cual puede resultar variable dependiendo de la zona; antigüedad ésta que resulta determinante para la identificación de aquellas prácticas de manejo (que en definitiva es lo que otorga el valor patrimonial a esos olivares) que se consideran relevantes culturalmente y que, en este caso, tienen que ver sobre todo con el marco de plantación de los olivos, los sistemas de riego, el tratamiento de la hierba y plagas, las técnicas de poda y, en menor medida, los medios y formas utilizados para la recogida de la aceituna. Todo ello con independencia del resto de valores materiales e inmateriales relacionados con la producción y comercialización del aceite y demás productos derivados de la aceituna y del olivo.

- El espacio delimitado como paisaje cultural debe incorporar todos aquellos elementos que hacen posible el desarrollo de la actividad agraria objeto de protección. Hecho éste que nos obliga en primer lugar a identificar cuál es la actividad agraria que queremos proteger. En este sentido las posibilidades son lógicamente enormes, ya que nos encontramos desde actividades muy localizadas (un pequeño oasis, el ruedo agrario de un pueblo de montaña, una granja, un cortijo, etc.) a otras de una enorme extensión territorial (las vegas de un río, los pastos de alta montaña, los cultivos de secano de una comarca, etc.). Aunque obviamente cada caso requerirá de unos criterios de delimitación propios, puede servir como referencia los utilizados para delimitar la Vega de Granada en la propuesta realizada por la Plataforma Salvemos la Vega para su declaración como BIC, Zona Patrimonial ${ }^{25}$.

remarcar que prácticamente todos los valores importantes que hoy podemos otorgarle a lo agrario proceden del pasado: sistemas de riego sostenibles, biodiversidad cultivada, comercio de proximidad, soberanía alimentaria, usos alimenticios, médicos o estéticos de los cultivos, etc. Sin embargo, en la actualidad la Agricultura ecológica o prácticas semejantes (en menor medida la Agroecología) se han apropiado de estos valores de lo agrario, minusvalorando en muchos casos las prácticas agrarias tradicionales o históricas.

25 .- Esta delimitación fue validada, desarrollada y formalizada posteriormente en el contexto del proyecto de Investigación PAGO, cuyo IP es el autor de este artículo. Sobre el movimiento de defensa de la Vega de Granada ver al respecto: ARREDONDO-GARRIDO, D., "Espacios en tránsito. Revitalización del paisaje cultural de la Vega de Granada", Estoa. Revista de la Facultad de Arquitectura y Urbanismo de la Universidad de Cuenca, 2021, nº 10(19), 149-160. doi: 10.18537/est.v010.n019.a13; CASTILLO 


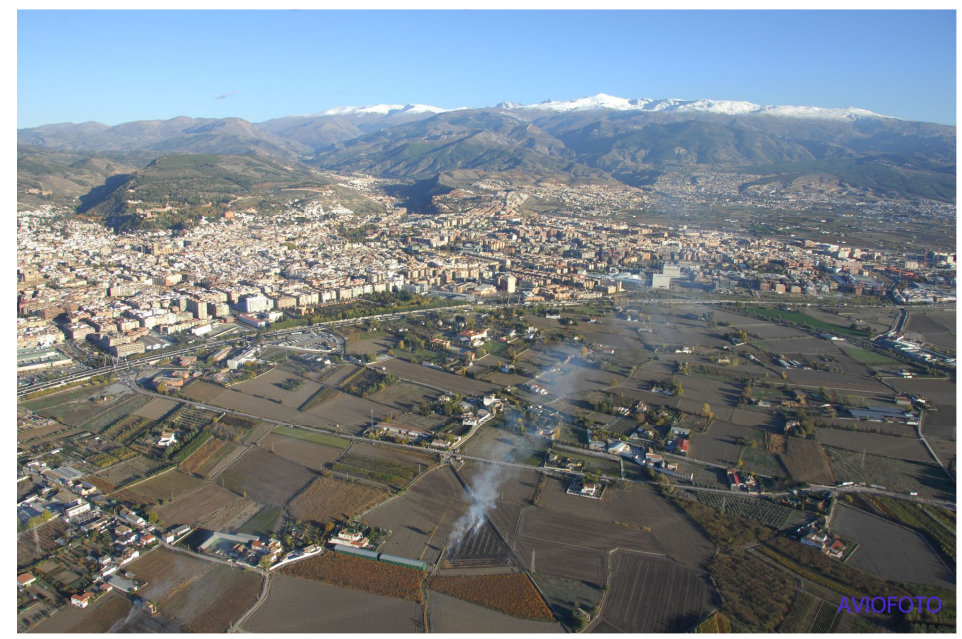

Fig. 9.- La Vega de Granada en su confluencia con la ciudad de Granada. (C) José Castillo Ruiz.

La Vega de Granada es ante todo y sobre todo un espacio agrario (fundamentalmente agrícola, aunque también ganadero) de carácter histórico (Fig.9). Es decir, un territorio en el que se encuentran una gran diversidad de bienes de diferente naturaleza y valor (materiales e inmateriales, naturales y culturales), los cuales han sido generados por la actividad agraria desarrollada sobre este espacio sin solución de continuidad desde época romana hasta la actualidad. Esto significa que la Vega de Granada no puede identificarse, defenderse o protegerse a través de la suma de elementos culturales o naturales aislados y descontextualizados (cortijos, fábricas, acequias, ríos, tierras, etc.), sino que debe hacerse desde una perspectiva holística como un espacio unitario, y único, resultado de esta actividad humana agrícola y ganadera desarrollada a lo largo de la historia. Una unidad que podríamos considerar como el resultado de la suma de esa diversidad de bienes generados por la actividad agraria a lo largo del tiempo (el río Genil y sus diferentes afluentes, con la riqueza natural biológica y zoológica asociada, especialmente en sus riberas; los suelos aluviales de excelente fertilidad agrícola; el patrimonio industrial generado por el cultivo de la remolacha durante los siglos XIX y XX; los omnipresentes secaderos como memoria de uno de los cultivos más importantes de la vega, el tabaco; las vías de comunicación y tránsito que estructuran la vega y permiten su interrelación;

RUIZ J. y MATARÁN RUIZ A., "La Vega de Granada: The Defence of a Paradigmatic Agrarian Heritage Space by Local Citizens", en SCAZZOSI L., BRANDUINI P. (eds), AgriCultura. Urban Agriculture, Springer, Cham. 2020, https://doi.org/10.1007/978-3-030-49012-6_14; CASTILLO RUIZ, J., "La "bictitis” o la alergia social (¿o es sólo política?), op. cit. 
la variabilidad y diversidad de sus paisajes; los importantes restos arqueológicos existentes; el relevante y diverso patrimonio arquitectónico y urbano de las diferentes localidades que ocupan la vega; la enorme variedad y riqueza de la arquitectura agraria, identificada a través de las huertas y los cortijos, sin olvidar los asentamientos urbanos y la arquitectura popular en ellos existentes; el interés y diversidad de las actividades, usos, técnicas, conocimientos y demás bienes intangibles asociados, sobre todo a las diferentes formas de explotación agrícola de la vega o, y de forma muy destacada por simbólica, la ejemplarizante y catártica presencia de Federico García Lorca $^{26}$ ), pero que realmente está posibilitada por el histórico sistema de riego, verdadero elemento definidor y estructurador de la Vega de Granada como ámbito funcional y patrimonial, de ahí que hayan sido los límites de este complejísimo y valiosísimo sistema hidráulico los utilizados por la Plataforma Salvemos la Vega como delimitación de la Zona Patrimonial propuesta ${ }^{27}$. (Fig.10)

Por esta razón, cuando la Junta de Andalucía, ante la clamorosa e insistente reclamación social de que protegiera la Vega de Granada como BIC (la cual fue rechazada de forma sistemática ${ }^{28}$,) ofreció a la sociedad un instrumento alternativo a esta declaración como fue la elaboración de un Plan especial de

26 .- De la numerosa bibliografía existentes sobre la Vega de Granada destacamos las siguientes publicaciones (por orden alfabético): CASTILLO RUIZ, J. y ROMERO GALLARDO, A. (coord..). Patrimonio cultural, remolacha y nuevas tecnologías. El paisaje agroindustrial de la remolacha en la Vega de Granada a partir de la reconstrucción en 3D de la Fábrica de Nuestro Señor de la Salud de Santa Fe, Granada, Universidad, 2019; CASTILLO VERGARA, A., Los tranvías de la Vega de Granada. El tranvía de santa Fe, las líneas interurbanas y el ferrocarril aéreo "Durcal-Motril, Granada, Proyecto Sur, 2003; CEJUDO GARCÍA, E. y CASTILLO RUIZ, J., "La Vega de Granada. La construcción patrimonial de un espacio agrario", en HERMOSILLA PLA, J. (dir.), Los regadios históricos españoles. Paisajes culturales, paisajes sostenibles, Valencia, Ministerio de Medio Ambiente y Medio Rural y Marino, 2010, pp. 243-284; GONZÁLEZ RUIZ, L., Origen y desarrollo del cultivo del tabaco en la provincia de Granada (1870-1960), Granada, Atrio, 2004; MENOR TORIBIO, J., La Vega de Granada: transformaciones agrarias recientes en un espacio periurbano, Granada, Universidad de Granada, 2000; OCAÑA OCAÑA, M. del C., La Vega de Granada. Estudio geográfico, Madrid, Instituto de Geografía Aplicada del Patronato "Alonso de Herrera" (C.S.I.C), Caja de Ahorros de Granada, 1971; PUENTE ASUERO, R., "La Vega de Granada: De un espacio agrario en crisis a un complejo paisaje cultural", Revista de Estudios Regionales, 2013, nº 96, pp. 181-213; REYES MESA, J. M. y GIMÉNEZ YANGUAS, M., Miradas desde el ferrocarril del azúcar: paisaje y patrimonio industrial en la Vega de Granada, Granada, Axares, 2014.

27 .- Ver al respecto CASTILLO RUIZ, J., MARTÍNEZ HIDALGO, C. y PÉREZ CÓRDOBA, G. "El sistema histórico de riego de la Vega de Granada. Reconocimiento y protección desde la perspectiva del Patrimonio Agrario", en Irrigation, Society and Landscape. Tribute to Tom F. Glick, Valencia, Editorial Universitat Politècnica de València, 2015, pp. 763-790. doi:10.4995/ISL2014.2014.190

28 .- CASTILLO RUIZ, J., “¿Por qué la Junta de Andalucía se niega a declarar la vega de Granada como BIC, zona patrimonial?", Revista PH. Instituto Andaluz del Patrimonio Histórico, 2016, nº 89, pp. $16-17$. 
ordenación ${ }^{29}$, éste fue duramente criticado por el movimiento de defensa ciudadano, entre otras razones porque los límites de la vega propuestos en dicho plan no eran los derivados del sistema hidráulico de riego (los demandados por el propio bien cultural) sino que estaban conformados por aquellos espacios (y de forma discontinúa) incluidos dentro de la clasificación de suelos no urbanizables en el POTAUG (Plan de Ordenación Territorial de la Aglomeración Urbana de Granada). Es decir, que para delimitar un bien, en este caso un territorio, de extraordinarios valores culturales y naturales se utilizaban criterios de tipo urbanístico o administrativo (la clasificación del suelo) y no los derivados de la propia naturaleza cultural del bien. Sería como establecer los límites de la Alhambra no en función, por ejemplo, de la extensión de su recinto fortificado sino de los límites del suelo urbano del municipio de Granada.

- Mención especial merecen los paisajes culturales relacionados con un determinado cultivo (la vid, el olivo, el café, el tabaco, el arroz, etc.) que, por otro lado, son los que hasta ahora están siendo objeto de reconocimiento patrimonial, especialmente por parte de la UNESCO. Si bien la elección de un cultivo como objeto patrimonial resulta totalmente procedente, lo cual además facilita enormemente las labores de delimitación del espacio a proteger (los espacios, todos o algunos, en los que se cultiva), su patrimonialización puede suponer importantes riesgos, sobre todo los derivados del implícito apoyo y reconocimiento del monocultivo que ello supone, el cual puede provocar una minusvaloración o exclusión de aquellos otros cultivos que concurren y confluyen en ese mismo territorio, los cuales también pueden ser generadores de un importante patrimonio agrario. Una práctica del monocultivo que además suele estar amparada y apoyada por otros mecanismos de protección paraculturales como las denominaciones de origen protegidas (DOP) y figuras similares que difiere de otras formas de conservación como las derivadas de las variedades locales ${ }^{30}$.

29 .- https://www.juntadeandalucia.es/organismos/fomentoinfraestructurasyordenaciondelterritorio/areas/ordenacion/actuaciones-supramunicipales/paginas/plan-vega-granada.html. Sobre los diferentes planes urbanísticos implementados a lo largo de la historia en la Vega de Granada ver ZURITA POVEDANO, E., "Evaluación y consecuencias de la planificación sobre la Vega de Granada: un paisaje cultural agrario en peligro", e_rph. Revista electrónica de patrimonio histórico, $\mathrm{n}^{\circ}$ 17, 2015, p. 5-28 https://revistaseug.ugr.es/index.php/erph/article/view/3945.

30 .- CASTILLO RUIZ, J. y RAMOS FONT, M. E. "Patrimonio genético agrario: reconocimiento y conservación", En CASTILLO RUIZ, J. y MARTÍNEZ YÁÑEZ, C. (coords.). El Patrimonio Agrario. La construcción cultural del territorio a través de la actividad agraria, Sevilla, UNIA, 2015, pp. 149182. https://www.unia.es/explorar-catalogo/item/patrimonio-agrario. 
Una cuestión relacionada con este reconocimiento patrimonial de los monocultivos es el hecho, habitualmente promovido desde la UNESCO, de seleccionar un determinada área o lugar como representativo de un determinado cultivo (el olivo, la manzana, el algodón, remolacha, café, etc.) tanto a nivel nacional como internacional. Este hecho supone otorgarle un grado de similitud y homogeneidad a la forma de laborear los cultivos que en absoluto se corresponde con la diversidad y variedad que éstos presentan según el territorio (y la sociedad) en el que se produzcan, pues estas variaciones pueden ser múltiples y referidas tanto a la orografía, el clima, las variedades locales, las formas de manejo, los conocimientos, celebraciones y demás bienes inmateriales asociados al mismo, etc. Al igual que no podemos declarar, por poner un ejemplo, el románico del Camino de Santiago como ejemplificación de todo el arte románico, así mismo no podemos declarar un determinado paisaje agrario, por ejemplo, el del olivo, como representante de todos los olivares cultivados en Andalucía, España o el Medite-
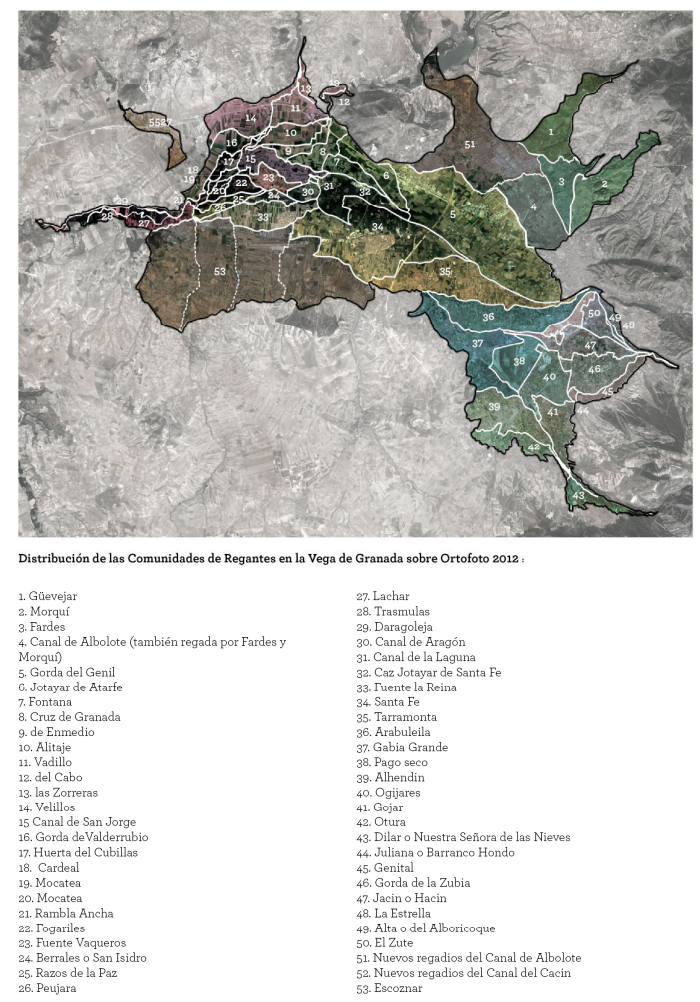
rráneo.

Fig. 10.- Delimitación de la Vega de Granada a partir de la suma del ámbito de riego de las Comunidades de Regantes de la Vega de Granada sobre

Ortofoto 2012. (c) Celia Martínez Hidalgo.

\section{BIBLIOGRAFÍA}

ARREDONDO-GARRIDO, D., "Espacios en tránsito. Revitalización del paisaje cultural de la Vega de Granada", Estoa. Revista de la Facultad de 
Arquitectura y Urbanismo de la Universidad de Cuenca, 2021, n 10(19), 149-160. doi: 10.18537/est.v010.n019.a13.

CASTILlO RUIZ, J. (dir.), La Carta de Baeza sobre Patrimonio Agrario, Sevi1la, UNIA, 2013. http://hdl.handle.net/10481/36377.

CASTILLO RUIZ, J., "El patrimonio cultural podría estar en peligro y los responsables son la memoria, la salvaguardia, la comunidad y el paisaje cultural (además del turismo, claro)", erph_revista electrónica de patrimonio histórico, $\mathrm{n}^{\mathrm{o}} 28,2021$, pp. 3-38. https://doi.org/10.30827/erph.vi28.21530.

CASTILLO RUIZ, J., "La “bictitis” o la alergia social (¿o es sólo política?) a la protección de los bienes culturales de carácter territorial. reflexiones y propuestas a partir del caso de la Vega de Granada", en CASTILLO MENA, A. (ed.), Personas y comunidades: Actas del Segundo Congreso Internacional de Buenas Prácticas en Patrimonio Mundial: (29 -30 de abril, 1 y 2 de mayo de 2015), Madrid, Universidad Complutense de Madrid, Servicio de Publicaciones, Madrid, 2015, p. 420. http://eprints.ucm.es/34899/.

CASTILLO RUIZ, J., “Por qué la Junta de Andalucía se niega a declarar la vega de Granada como BIC, zona patrimonial?", Revista PH. Instituto Andaluz del Patrimonio Histórico, 2016, nº 89, pp. 16-17.

CASTILLO RUIZ J. y MATARÁN RUIZ A., "La Vega de Granada: The Defence of a Paradigmatic Agrarian Heritage Space by Local Citizens", en SCAZZOSI L., BRANDUINI P. (eds), AgriCultura. Urban Agriculture, Springer, Cham. 2020, https://doi.org/10.1007/978-3-030-49012-6_14

CASTILlO RUIZ, J. y ROMERO GALLARDO, A. (coord..). Patrimonio cultural, remolacha y nuevas tecnologías. El paisaje agroindustrial de la remolacha en la Vega de Granada a partir de la reconstrucción en 3D de la Fábrica de Nuestro Señor de la Salud de Santa Fe, Granada, Universidad, 2019. CASTILLO RUIZ, J., MARTÍNEZ HIDALGO, C. y PÉREZ CÓRDOBA, G. "El sistema histórico de riego de la Vega de Granada. Reconocimiento y protección desde la perspectiva del Patrimonio Agrario", en Irrigation, Society and Landscape. Tribute to Tom F. Glick, Valencia, Editorial Universitat Politècnica de València, 2015, pp. 763-790. doi:10.4995/ISL201 4.2014.190.

CASTILLO RUIZ, J. y RAMOS FONT, M. E. "Patrimonio genético agrario: reconocimiento y conservación", En CASTILLO RUIZ, J. y MARTÍNEZ YÁÑEZ, C. (coords.). El Patrimonio Agrario. La construcción cultural del territorio a través de la actividad agraria, Sevilla, UNIA, 2015, pp. 149-182. https:/www.unia.es/explorar-catalogo/item/patrimonio-agrario.

CASTILLO VERGARA, A., Los tranvías de la Vega de Granada. El tranvía de santa Fe, las líneas interurbanas y el ferrocarril aéreo "Durcal-Motril, Granada, Proyecto Sur, 2003. 
CEJUDO GARCÍA, E. y CASTILLO RUIZ, J., "La Vega de Granada. La construcción patrimonial de un espacio agrario", en HERMOSILLA PLA, J. (dir.), Los regadios históricos españoles. Paisajes culturales, paisajes sostenibles, Valencia, Ministerio de Medio Ambiente y Medio Rural y Marino, 2010, pp. 243-284.

CARRIÓN GÚTIEZ, A., Plan Nacional de Paisaje Cultural, Madrid, Ministerio de Educación, Cultura y Deporte, 2015.

FERNÁNDEZ CACHO, S. et al., "Balance y perspectivas del Registro de Paisajes de Interés Cultural de Andalucía", $P H, n^{\circ} 88$, octubre 2015, pp. 166-189).

FERNÁNDEZ LACOMBA, J., ROLDÁN, F. y ZOIDO, F. (coord.), Territorio y patrimonio. Los paisajes andaluces, Sevilla, Consejería de Cultura, Comares, 2003.

FERNÁNDEZ SALINAS V., "Los paisajes de interés cultural de Asturias", Revista de geografia Ería, no 91, 2013, pp. 129-149.

FERNÁNDEZ SALINAS, V. y SILVA PÉREZ, R., "Criterios para la identificación y selección de paisajes españoles susceptibles de ser incluidos en la lista del Patrimonio Mundial de UNESCO”, Boletín de la Asociación de Geógrafos Españoles, 2015, nº. 68, p. 253-278.

FERNÁNDEZ SALINAS, V. y SILVA PÉREZ, R., "Deconstruyendo los paisajes culturales de la Lista del Patrimonio Mundial de la Unesco", Cuadernos Geográficos, n 55, 2016, pp. 176-197.

GÓMEZ-LIMÓN RODRÍGUEZ, J. A. BARREIRO HURLÉ, J., MÁRMOL, E. y MARCOS, C. (coord.), La multifuncionalidad de la agricultura en España. Concepto, aspectos horizontales, cuantificación y casos prácticos, Madrid, Ministerio de Agricultura, Alimentación y Medio Ambiente, 2007.

GONZÁLEZ RUIZ, L., Origen y desarrollo del cultivo del tabaco en la provincia de Granada (1870-1960), Granada, Atrio, 2004.

LOZANO BARTOLOZZI, Ma del M. y MÉNDEZ HERNÁN, V. (coords. y eds.), Patrimonio cultural vinculado al agua. Paisaje, urbanismos, arte, ingeniería y turismo, Mérida, Editorial Regional de Extremadura, 2014.

MARTÍNEZ YÁÑEZ, C. "El Patrimonio Agrario inscrito en la Lista del Patrimonio Mundial: Tipos de bienes, modelos de gestión y desafíos", en CASTILLO RUIZ, J. y MARTÍNEZ YÁÑEZ, C. (coord.), El Patrimonio Agrario. La construcción cultural del territorio a través de la actividad agraria, Sevilla, UNIA, 2015, pp.183-229.

MARTÍNEZ YÁÑEZ, C. "Los paisajes agroindustriales en la Lista del Patrimonio Mundial. Agricultura versus Industria", en CASTILLO RUIZ, J. y ROMERO GALLARDO, A. (coord..). Patrimonio cultural, remolacha y nuevas tecnologias. El paisaje agroindustrial de la remolacha en la Vega de 
Granada a partir de la reconstrucción en 3D de la Fábrica de Nuestro Señor de la Salud de Santa Fe, Granada, Universidad, 2019, pp. 37-58.

MENOR TORIBIO, J., La Vega de Granada: transformaciones agrarias recientes en un espacio periurbano, Granada, Universidad de Granada, 2000.

MOLINERO, F (coord.), Atlas de los Paisajes Agrarios de España. Tomo I. Las clases de paisajes agrarios de España. Las unidades de paisaje agrario de la España atlántica, Madrid, Ministerio de Agricultura, Alimentación y Medio Ambiente, 2013.

MOLINERO, F (coord.), Atlas de los Paisajes Agrarios de España. Tomo II. Las unidades de paisaje agrario de la España mediterránea, Madrid, Ministerio de Agricultura, Alimentación y Medio Ambiente, 2014

OCAÑA OCAÑA, M. del C., La Vega de Granada. Estudio geográfico, Madrid, Instituto de Geografía Aplicada del Patronato "Alonso de Herrera" (C.S.I.C), Caja de Ahorros de Granada, 1971.

PUENTE ASUERO, R., "La Vega de Granada: De un espacio agrario en crisis a un complejo paisaje cultural”, Revista de Estudios Regionales, 2013, n ${ }^{\circ}$ 96, pp. 181-213.

REYES MESA, J. M. y GIMÉNEZ YANGUAS, M., Miradas desde el ferrocarril del azúcar: paisaje y patrimonio industrial en la Vega de Granada, Granada, Axares, 2014.

SILVA PÉREZ, R. y FERNÁNDEZ SALINAS, V., "El nuevo paradigma del patrimonio y su consideración con los paisajes: Conceptos, métodos y prospectiva", Documents d'Anàlisi Geogràfica, vol. 63/1, 2017, pp. 129-151.

ZOIDO, F. y VENEGAS, C. (Coord.), Paisaje y Ordenación del Territorio, Sevilla, Consejería de Obras Públicas y Transportes y Fundación Duques de Soria, 2002.

ZURITA POVEDANO, E., "Evaluación y consecuencias de la planificación sobre la Vega de Granada: un paisaje cultural agrario en peligro", e_rph. Revista electrónica de patrimonio histórico, $\mathrm{n}^{\circ}$ 17, 2015, p. 5-28 https://revistaseug.ugr.es/index.php/erph/article/view/3945.

José Castillo Ruiz

Departamento de Historia del Arte

Universidad de Granada

jcastill@ugr.es 